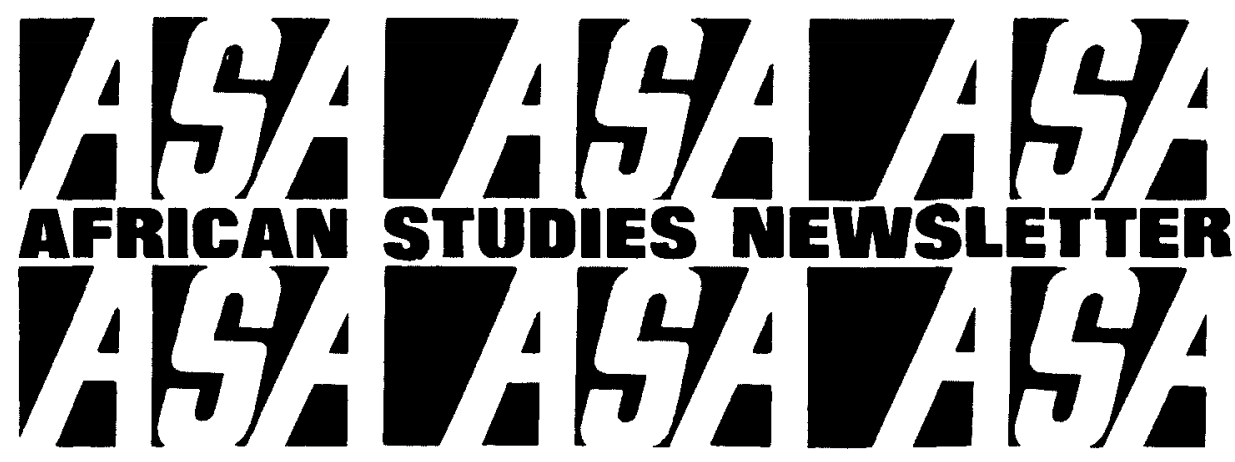

\title{
CONTENTS
}

Election Results . . . . . . . . . . . . . .

Archives-Libraries Committee Resolution on

Migrated Archives . . . . . . . . . . . . . .

Research Opportunities: Botswana . . . . . . . . . . . .

Financial Statement . . . . . . . . . . . . . . . .4

In Memoriam: Carlo Giglio . . . . . . . . . . . . . . . 5

Meetings-Past \& Future . . . . . . . . . . . . . .6

Special Announcements . . . . . . . . . . . . . . . . .8

Grants \& Awards . . . . . . . . . . . . . . . . . . . . . 11

Employment . . . . . . . . . . . . . . . . . . . 12

Liberation Support Groups in Europe . . . . . . . . . . . . . . 14

Annual Meeting Papers/Canadian Association of African

Studies . . . . . . . . . . . . . . 16

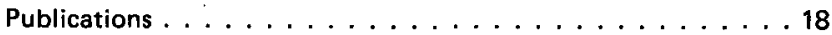

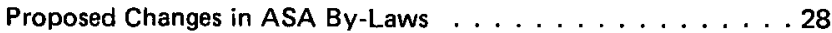

News from Foreign Research Institutes . . . . . . . . . 30

Note of Concern from the Open Forum and

Current Issues Committee . . . . . . . . . . . . . . 31

\section{ELECTION RESULTS}

The results of the 1977 elections for vice president and members of the Board of Directors of the African Studies Association are:

Elected for vice president:

Elected for Board of Directors:

\section{William Foltz \\ Lansine Kaba \\ Priscilla Reining}

The vote on the Board's resolution ("It is appropriate for resolutions on political issues that arise in relation to African affairs to be moved, debated, and voted upon at the annual business meeting.") was 290 disapproving and 222 approving. 